\begin{tabular}{|c|c|c|c|}
\hline & \multirow{4}{*}{$\begin{array}{c}\text { International Journal of Herbal Medicine } \\
\text { Available online at www.florajournal.com }\end{array}$} & $\mathbf{I}$ & \multirow{4}{*}{$\begin{array}{l}\text { Interuactunau } \\
\text { Journal } \\
\text { of } \\
\text { Herbal } \\
\text { Medicine }\end{array}$} \\
\hline & & $\bar{J}$ & \\
\hline & & $\mathbf{H}$ & \\
\hline & & $\mathbf{N I}$ & \\
\hline
\end{tabular}

E-ISSN: 2321-2187 P-ISSN: 2394-0514 IJHM 2016; 4(6): 158-161

Received: 13-09-2016 Accepted: 14-10-2016

\section{Abderrahim Benslama} Department of Nature and Life Sciences, Faculty of Exact, Nature and Life Sciences, University of Biskra, Algeria

Abdenassar Harrar Department of Nature and Life Sciences, Faculty of Sciences, University of Msila, Algeria

Correspondence

\section{Free radicals scavenging activity and reducing power of two Algerian Sahara medicinal plants extracts}

\author{
Abderrahim Benslama and Abdenassar Harrar
}

\begin{abstract}
The aim of this study is to evaluate antioxidant activity of aqueous (Aq.E) and methanolic (Met.E) extracts of Zygophyllum album L. (Zygophyllaceae) and Arthrophytum scoparium (Chenpodiacea), two medicinal plant from Algerian Sahara used in traditional pharmacopoeia. The results showed that Aq.E have the heights yields $24 \%$ and $22.3 \%$ for Z album and A. scoparium respectively. Qualitative analysis of showed that the Met.E of Z. album of had the highest amount of polyphenols $(202.26 \pm 4.73 \mu \mathrm{g}$ GAE/mg E) and flavonoids ( $15.77 \pm 0.94 \mu \mathrm{g} \mathrm{QE} / \mathrm{mg}$ E). The antioxidant activity of extracts was evaluated by 2, 2'-diphenyl-1-picrylhydrazyl (DPPH) and reducing power assay. Results showed that the extracts of A. scoparium. Have the highest free radical scavenger activity in DPPH test $\left(\mathrm{EC}_{50}=0.096 \pm 0.001\right.$ and $0.108 \pm 0.002 \mathrm{mg} / \mathrm{ml}$ for Met.E and Aq.E respectively). In addition, the results of reducing power assay demonstrated that Met.E of Z. album had the highest effect with $2399.65 \pm 12.31 \mu \mathrm{g}$ ascorbic acid equivalent/mg E.Our results showed that the methanolic extract reported a considerable free radicals scavenging activity and reducing effect, may be due to their richness on polyphenols and flavonoids.
\end{abstract}

Keywords: A. scoparium, Z. album, antioxidant activity, medicinal plants polyphenols, flavonoids

\section{Introduction}

Medicinal plants have been used since ancient times to relieve and cure diseases human. In fact, their therapeutic properties are due to the presence of thousands of bioactive natural compounds. There is increasing trend in correlating phytochemical constituents of plants with its pharmacological activities. Leaves, flowers, stems, roots, seeds, fruit and bark can all be constituents of herbal medicines ${ }^{[1]}$. Phenolicsor polyphenols are secondary plant metabolites that are ubiquitously present in plants and plant products; they have several biological and pharmacological effects such as anti-inflammatory, antispasmodic, ant-iallergic, anti-diabetic, antimicrobial and antiviral ${ }^{[2,3]}$. The oxidative stress is the majority cause of pathological disorders and disease such as aging, diabetes, cardiovascular diseases and cancer. Whatever the case, the risk is increased with the accumulation of reactive oxygen species (ROS) such as superoxide anion $\left(\mathrm{O}^{*}-\right)$, hydroxyl radicals $\left(\mathrm{OH}^{*}\right)$ and hydrogen peroxide $\left(\mathrm{H}_{2} \mathrm{O}_{2}\right)$. ROS leading to a radical reaction chain which degrades organic molecules vital to know the DNA, lipids and proteins in the body, which have been implicated in the etiology and pathophysiology $[4$, ${ }^{5]}$.In recent years increased interest is observed on the biological effects of natural antioxidant included in the fight against oxidative stress involved in the initiation and progression of several diseases. In addition, many of the phenolic compounds have been shown to contain high levels of antioxidant and antimicrobial activities ${ }^{[6]}$. The aim of this study consisted to valorization of medicinal and aromatic plants of the Algeria flora, in order to evaluate the total polyphenols contents and the antioxidant activity of extracts of Z. album and A. scoparium, tow Algerian Sahara plants used in various folk medicines.

\section{Materials and Methods \\ 2.1 Materials}

Zygophyllum album L. (Zygophyllaceae) and Arthrophytum scoparium (Chenopodiaceae) are widely distributed in the south of Algeria. Locally named "Bougriba" and "Elremth" respectively, which have been used traditionally in Algerian folk medicine. The plant materials were collected in December 2014, from Biskra (south of Algeria), authenticated by Dr. Salemkour N, the center of scientific and technical research on arid regions (C.R.S.T.R.A), Biskra, Algeria. The aerial part of plants is dried at temperature room then powdered using a blender and is storedin the dark crushed up in stock until use.

2,2-diphenyl-2-picryl-hydrazil (DPPH), aluminum chloride $\left(\mathrm{AlCl}_{3}\right)$, potassium ferricyanide $\left[\mathrm{K}_{3} \mathrm{Fe}(\mathrm{CN})_{6}\right]$, trichloroacetic acid (TCA), iron chloride $\left(\mathrm{FeCl}_{3}\right)$ sodium carbonate $\left(\mathrm{Na}_{2} \mathrm{CO}_{3}\right)$, ascorbic acid, Folin-Ciocalteau reagent, gallic acid, quercetin, rutin and 2, 6 di-tertbutyl-4-methyl phenol (BHT). These products were purchased from Sigma Chemicals, SigmaAldrich. 


\subsection{Methods}

\subsubsection{Preparation of extract}

The extractions were carried from the aerial part plants by methanol and distilled water according to the method of ${ }^{[7-8]}$. The extraction of powdered plant material was carried out by maceration process for $24 \mathrm{~h}$. The powdered plant material (10 g) was soaked in $100 \mathrm{ml}$ of methanol or distilled water. The extract was filtered using a Buchner funnel and Whatman No. 1 filter paper to obtain aqueous extract. The same procedure to obtain the methanolic extract. The extracts were stored at room temperature until use.

\subsubsection{Determination of total phenolic and flavonoids contents}

The total phenolic contents of the extracts were measured using the Folin-Ciocalteau colorimetric method described by [9], with gallic acid as standard. Basically, $0.2 \mathrm{ml}$ of extract was mixed with $1 \mathrm{ml}$ of Folin-Ciocalteau phenol reagent (10fold diluted). After $4 \mathrm{~min}, 0.8 \mathrm{ml}$ of saturated sodium carbonate $\mathrm{Na}_{2} \mathrm{CO}_{3}(7.5 \%)$ solution was added and the mixture was allowed to stand for $2 \mathrm{~h}$. Absorbance was measured at $765 \mathrm{~nm}$. The same procedure was repeated with all standard gallic acid solutions $(10-200 \mu \mathrm{g} / \mathrm{ml})$. The amount of total polyphenols in different extracts were expressed as $\mu \mathrm{g}$ of gallic acid equivalent (GAE)/ mg extract.

Flavonoids were quantified using aluminum chloride reagent $\left(\mathrm{AlCl}_{3}\right)$ method described by ${ }^{[10]}$. The flavonoids content was expressed as quercetin equivalents (QE). Briefly, $1 \mathrm{ml}$ of extract, dissolved in corresponding solvent was added to $1 \mathrm{ml}$ of $\mathrm{AlCl}_{3}(2 \%$ in methanol). The absorbance was measured at $430 \mathrm{~nm}$, after incubation at room temperature for $10 \mathrm{~min}$.

\subsubsection{DPPH radical scavenging assay}

The free radical scavenging activity of extracts was evaluated by 2,2-diphenyl-2-picryl-hydrazil (DPPH) scavenging assay according to the method reported by assay ${ }^{[11]}$. Briefly, $50 \mu 1$ of solution at different doses containing the compound to be tested were added to $1250 \mu \mathrm{l}$ of solution of DPPH (2.4 mg in $100 \mathrm{ml}$ methanol). The studied extracts were tested with methanol as control, BHT, gallic acid, rutin and quercetin as antioxidant-standards. Absorbance was measured at $517 \mathrm{~nm}$ that was determined after allowed to stand at room temperature for $30 \mathrm{~min}$. The absorbance of the control and samples was measured, and the DPPH scavenging activity in percentage was determined was calculated according to the following formula: Scavenging effect $\%=[(\mathrm{AC}-\mathrm{AS}) / \mathrm{AC}] \times$ 100

Where Ac: control absorbance and As: absorbance in presence of sample (extract). The data are presented as mean of triplicate and the concentration required for a $50 \%\left(\mathrm{EC}_{50}\right)$ reduction of DPPH radical was determined graphically.

\subsubsection{Reducing power assay}

The ability of extracts to reduce ferric ions $\left(\mathrm{Fe}^{+3}\right)$ was assessed by the method of ${ }^{[12]} .800 \mu \mathrm{l}$ of extract was mixed with $400 \mu \mathrm{l}$ phosphate buffer $(0.2 \mathrm{M}, \mathrm{pH}=6.6)$ and $800 \mu \mathrm{l}$ of a $1 \%$ potassium ferricyanide $\left[\mathrm{K}_{3} \mathrm{Fe}(\mathrm{CN})_{6}\right]$, then the mixture was incubated at $50{ }^{\circ} \mathrm{C}$ for $20 \mathrm{~min}$. About $800 \mu \mathrm{l}(10 \%)$ of trichloroacetic acid (TCA) was added to the mixture and centrifuged for $10 \mathrm{~min}(3000 \mathrm{r} / \mathrm{t})$. Finally, $400 \mu \mathrm{l}$ of the supernatant solution was mixed with $400 \mu \mathrm{l}$ of distilled water and $80 \mu \mathrm{FeCl}_{3}(0.1 \%)$ and the absorbance was recorded at $700 \mathrm{~nm}$. Increased absorbance of the reaction mixture indicated increased reducing power. The results were expressed as $\mu \mathrm{g}$ ascorbic acid equivalent/mg extract ${ }^{[13]}$.

\subsection{Statistical analysis}

Experimental results were expressed as mean \pm SD of triplicate. The data were analysed by Student's $t$-test to determine statistical significance. $p$-values and $p<0.05$ was considered as indicative of significance. The $\mathrm{EC}_{50}$ values were calculated from linear regression analysis. All statistical analysis and graphing of data were performed using Graph pad prism 5 software.

\section{Results and discussion}

3.1 Extraction and Total phenolic and flavonoid contents Extract was dried with rapport of $1 / 10(\mathrm{w} / \mathrm{v})$ under reduced pressure giving different yields The total phenolic and flavonoid contents in the extracts was determined spectrophotometrically, using Folin-Ciocalteu and aluminum chloride methods, respectively (Table 1). Results showed that the methanolic extract of the two plants contain the highest amounts of phenolic compounds andflavonoids (Table 1).Moreover, the Methanolic extract of Z. album L. contained the highest amount of polyphenols and flavonoids compared to the Met.E of $A$. scoparium. In addition, The Aq.E of $A$. scoparium showed the highest amount of polyphenolscompared to the Aq. Eof Z. album L. extract of total phenolic contents in plant extracts depend on the type of extract, i.e. the polarity of solvent used in extraction. High solubility of phenols in polar solvents provides high concentration of these compounds in the extracts obtained using polar solvents for the extraction. The concentration of flavonoids in plant extracts depends on the polarity of solvents used in the extract preparation ${ }^{[14,15]}$.

Table 1: Total polyphenol and flavonoids contents of extracts.

\begin{tabular}{|c|c|c|c|c|c|c|}
\hline & \multicolumn{2}{|c|}{ Yield (\%) } & \multicolumn{2}{|c|}{ Polyphenols contents ( $\mu$ g GAE/mg E) } & \multicolumn{2}{|c|}{ Flavonoids (contents $\mu \mathrm{g} \mathrm{QE} / \mathrm{mg} \mathrm{E}$ ) } \\
\hline & Met.E & Aq.E & Met.E & Aq.E & Met.E & Aq.E \\
\hline Z. album L. & 11.6 & 24 & $202.26 \pm 4.73$ & $46.37 \pm 2.20$ & $15.77 \pm 0.94$ & $1.95 \pm 0.13$ \\
\hline A. scoparium & 10.8 & 22.3 & $142.98 \pm 3.76$ & $133.52 \pm 2.47$ & $6.94 \pm 0.89$ & $4.72 \pm 0.79$ \\
\hline
\end{tabular}

The results of ${ }^{[16]}$ have shown that the polyphenol contents of the methanol extract that is greater than the aqueous extract although the study is carried out on the Capparis spinosa L. Therefore, many studies demonstrated that polar solvents give higher yields than apolar solvents, since the polar solvents have the ability to spread within the plant powder, reaching the vegetable matrix and therefore recover the possible metabolites. While non-polar solvents which are immiscible with water, does not have the ability to extract the maximum amount of bioactive molecules because of the presence of the water contained in the plant tissue ${ }^{[17]}$.

\subsection{The antiradical activity using DPPH assay}

DPPH radicals are widely used in the model system to investigate the scavenging activities of several natural compounds. When DPPH radical is scavenged, the color of the reaction mixture changed from purple to yellow with decreasing of absorbance at wavelength $517 \mathrm{~nm}$. The antioxidant activity of different extracts was determined using DPPH radical scavenging test then antiradical activity was 
expressed by effective concentration $\left(\mathrm{EC}_{50}\right)$. DPPH radical scavenging activity of the extracts is shown in Fig. 1. The results showed that both extracts of $A$. scoparium possess a height antiradical activity with $\left(\mathrm{EC}_{50}=0.096 \pm 0.001\right.$ and $0.108 \pm 0.002 \mathrm{mg} / \mathrm{ml}$ for Met. E and Aq. E respectively), thisEC $\mathrm{C}_{50}$ values are not significantly different compared with BHT).Moreover, The Z. Met. E and Z. Aq. E present less $\mathrm{DPPH}$ free radical scavenging activity with $\left(\mathrm{EC}_{50}=0.46 \pm 0.01\right.$ and $1.23 \pm 0.02 \mathrm{mg} / \mathrm{ml}$, respectively). It has been reported that the antiradical activity of tea extracts is probably due to their hydrogen donating ability attributed to polyphenols components ${ }^{[18]}$. In addition, the antioxidant properties of phenolic compounds are attributed in part to the ability of these compounds to scavenge free radicals such as superoxide anion $\left(\mathrm{O}^{-}{ }^{-}\right)$, hydroxyl radicals $\left(\mathrm{OH}^{*}\right)$ and hydrogen peroxide $\left(\mathrm{H}_{2} \mathrm{O}_{2}\right)^{[19]}$. The antiradical activity of natural antioxidants such as phenolic compounds and flavonoids may be due to their richness by hydroxyl-ring. The spatial configuration and the number of $\mathrm{OH}$ group of flavonoid structures can influence the different antioxidant mechanisms ${ }^{[20]}$.

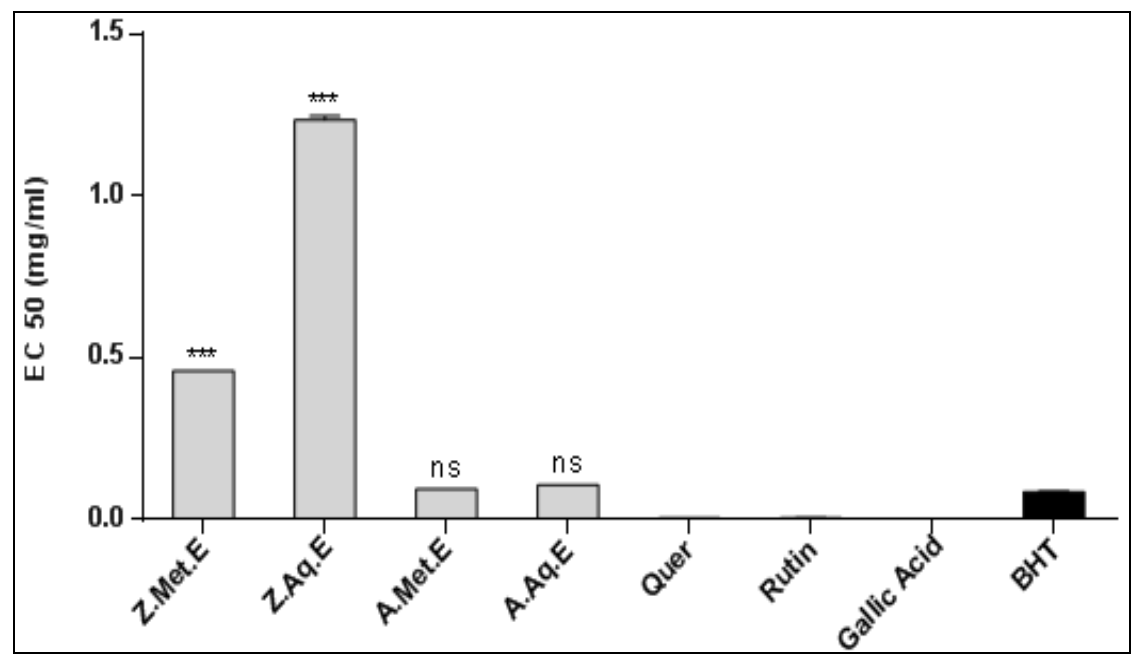

Fig 1: $\mathrm{EC}_{50}$ values in Free radical scavenging activity of the extracts against DPPH free radical. Values were means \pm SD of triplicate (ns:p $>$ $0.05, *: p \leq 0.05, * *: p \leq 0.01, * * *: p \leq 0.001)$.

\subsection{Reducing power}

The ability of extract to reduce $\mathrm{Fe}^{+3}$ to $\mathrm{Fe}^{+2}$ (reducing effect) was determined according to the method described by ${ }^{[12]}$. The reducing capacity of a compound may serve as a significant indicator of its potential antioxidant activity ${ }^{[21]}$.Dietary antioxidant such as ascorbic acid was used for comparison. Compounds with reducing power indicate that they are electron donors and can reduce the oxidized intermediates of lipid peroxidation processes, so that they can act as primary and secondary antioxidants ${ }^{[22]}$. The results were expressed as $\mu \mathrm{g}$ ascorbic acid equ/mg extract. The Met.E of Z. album have strong reducing capacity $(2399.65 \pm 12.31 \mu \mathrm{g}$ AAequ $/ \mathrm{mg} \mathrm{E})$ this capacity is more best than capacity of quercetin (2109.72 $\pm 15.49 \mu \mathrm{g}$ AAequ/mg Q). However, the reducing capacity of A. scoparium is less than the reducing capacity of Z. albumextracts.

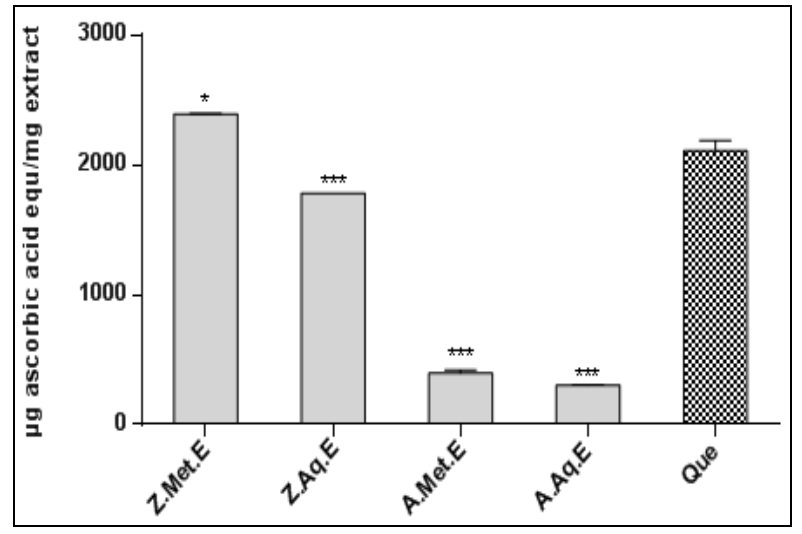

Fig 2: The reducing power of extracts and quercetin. Values were expressed as means $\pm \mathrm{SD}$ of triplicate. (ns: $p>0.05 ; * p: \leq 0.05$; $* * *: p \leq 0.001)$.
The reducing power of a compound set referred to its electron transfer capacity in a redox reaction, leading to the conversion of free radicals in less reactive or inert products. However, in addition to stabilizing the radical cation, the buffer systems by controlling the ratio of the protonated or deprotonated states of the antioxidants could result in an "induced antioxidant" activity ${ }^{[23]}$. The reducing capacity of antioxidant be due to their electron transfer property such as polyphenols flavonoids. Many studies demonstrated that the plants extract possess a strong reducing capacity. In other hand, many researchers has been widely reported the relationship between polyphenol structure and their and ferric reducing capacity ${ }^{[24,}$ 26]. Phenolic compounds are called antioxidants because of their ability to scavenge free radicals, lipid peroxidation inhibition, and reducing effect ${ }^{[27,20]}$.

\section{Conclusion}

On the basis of the results of this study, the methanolic have a height antioxidant activity may be due to their phenolic contents in extracts, it possessedexcellent antioxidant properties, including scavenging abilities against DPPH and reducing power. Moreover, The A. scoparium extracts exhibited a strong antiradical 1 activity against DPPH free radical. When, the $Z$. album extracts exhibited a highest reducing capacity. In conclusion, the antioxidants activity of extract may be due to the nature of compounds in each extract. In view of the potential use of $A$. scoparium and $Z$. lotus extracts in therapeutic benefits and bioactive compounds warrant for further in vitro and in vivo investigations.

\section{Acknowledgments}

We would like to thank by Dr. Salemkour N, the center of scientific and technical research on arid regions (C.R.S.T.R.A), Biskra, Algeria, for the identification of the plant material. 


\section{References}

1. Gurib-Fakim A. Medicinal plants: traditions of yesterday and drugs of tomorrow. Molecular Aspects of Medicine. 2006; 27:1-93.

2. Winston JC. Health-promoting properties of common herbs. American Journal of Clinical Nutrition. 1999; 70:491-499.

3. Halliwell B, Gutteridge JMC, Cross CE. Free radicals, antioxidants, and human disease: Where are we now Journal of Laboratory and Clinic Medical? 1992; 119:598.620.

4. Exarchou V, Nenadis M, Tsimidou IP, Gerothanassis A, Troganis D, Boskou. Antioxidant activities and phenolic composition of extracts from Greek oregano, Greek sage, and Summer savory. Journal of Agriculture and Food Chemistry. 2002; 50:5294-5299.

5. Afanas'ev I. Signaling and damaging functions of free radicals in aging-free radical theory, hormesis, and TOR. Aging and Diseases. 2010; 1(2):75-88.

6. Choi BS, Sapkota K, Kim S, Lee HJ, Choi HS, Kim SJ. Antioxidant activity and protective effects of Tripterygium regelii extract on hydrogen peroxideinduced injury in human dopaminergic cells, SH-SY5Y. Neurochemical Research. 2010; 35:1269-1280.

7. Ljubuncic P, Song H, Cogan U, Azaizeh H, Bomzon A. The effect of aqueous extracts prepared from the leaves of Pistacia lentiscus experimental liver disease. Journal of Ethnopharmacology. 2005; 100:198-204.

8. Motamed SM, Naghibi F. Antioxidant activity of some edible plants of the Turkmen sahra region in northern in Iran. Food Chemistry. 2010; 119:1637-1642.

9. Li HB, Cheng KW, Wong CC, Fan KW, Chen FD, Jiang YS. Evaluation of antioxidant capacity and total phenolic content of different fractions of selected microalgae. Food Chemistry. 2007; 102:771-776.

10. Bahorun T, Aumjaud E, Ramphul H, Rycha M, Luximon RA, Trotin F, et al. Phenolic constituents and antioxidant capacities of Crataegus monogyna (Hawthorn) callus extracts. Nahrung. 2003; 47(3):191-198.

11. Cheel J, Theoduloz C, Rodriguez J, SchmedaHirschmann G. Free radical scavengers and antioxidants from Lemongrass (Cymbopogon citratus (DC.) Stapf.). Journal of Agriculture and Food Chemistry. 2005; 53(7):2511-2517.

12. Oyaizu M. Studies on product of browning reaction prepared from glucose amine. Japan Journal of Nutrition. 1986; 44:307-315.

13. Hemalatha A, Girija K, Parthiban C, Saranya C, Anantharaman P. Antioxidant properties and total phenolic content of a marine diatom, Navicula clavata and green microalgae, Chlorella marina and Dunaliella salina. Advances in Applied Science Research. 2013; $4: 151-157$.

14. Stanković MS. Total phenolic content, flavonoïd concentration and antioxidant activity of Marrubium peregrinum L. extracts. Kragujevac Journal of Sciences. 2011; 33:63-72.

15. Do QD, Angkawijaya AE, Tran-Nguyen PL, Huynh LH, Soetaredjo FE, Ismadji $\mathrm{S}$, et al. Effect of extraction solvent on total phenol content, total flavonoid content, and antioxidant activity of Limnophila aromatic. Journal of Food and Drug Analysis. 2014; 22(3):296-302.

16. Meddour A, Yahia M, Benkiki N, Ayachi A. Etude de l'activité antioxydante et antibactérienne des extraits d'un ensemble des parties de la fleur du Capparis spinosa L. Lebanon Scientific Journal. 2013; 14(1):49-60.
17. Ghedadba N, Hambaba L, Aberkane MC, Oueld-Mokhtar SM, Fercha N, Bousselsela H. Évaluation de l'activité hémostatique in vitro de l'extrait aqueux des feuilles de Marrubium vulgare L. Algerian Journal of Natural Products. 2014; 2(2):64-74.

18. Vukics V, Kery A, Bonn GK, Guttman A. Major flavonoid components of heartsease (Viola tricolor L.) and their antioxidant activities. Analytic and Bioanalytic Chemistry. 2008; 390:1917-1925.

19. Popovici C, Saykova I, Tylkowski B. Evaluation de l'activité antioxydant des composés phénoliques par la réactivité avec le radical libre DPPH. Revue de génie industriel. 2009; 4:25-39.

20. Pietta PG. Flavonoids as antioxidants. Journal of Natural Products. 2000; 63:1035-1042.

21. Chung YC, Chang CT, Chao WW, Lin CF, Chou ST. Antioxidative activity and safety of the $50 \%$ ethanolic extract from red bean fermented by Bacillus subtilis IMR-NK1. Journal of Agriculture and Food Chemistry. 2002; 50:2450-2454.

22. Chanda $\mathrm{S}$, Dave $\mathrm{R}$. In vitro models for antioxidant activity evaluation and some medicinal plants possessing antioxidant properties: An overview. African Journal of Microbiology Research. 2009; 13:981-996.

23. Re R, Pellegrini N, Proteggente A, Pannala A, Yang M, Rice-Evans C. Antioxidant activity applying and improved ABTS radical cation decolorization assay. Free Radical Biology and Medicine. 1999; 26:1231-1237.

24. Benzie IF, Strain JJ. The ferric reducing ability of plasma (FRAP) as a measure of "antioxidant power: the FRAP assay. Analytical Biochemistry. 1996; 239:70-76.

25. Pulido R, Bravo L, Saura-Calixto F. Antioxidant activity of dietary polyphenols as determined by a modified ferric reducing/ antioxidant power assay. Journal of Agriculture and Food Chemistry. 2000; 48:3396-3402.

26. Parejo I, Viladomat F, Bastida J, Rosas-Romero A, Saavedra G, Murcia MA, et al. Investigation of Bolivian plant extracts for their radical scavenging activity and antioxidant activity. Life Sciences. 2003; 73:1667-1681.

27. Maksimović Z, Malenčić D, Kovačević N. Polyphenol contents and antioxidant activity of Maydis stigma extracts. Bio-resources Technology. 2005; 96:873-877. 